\title{
Partial Differential Equations for Cereal Seeds Distribution
}

\author{
Kurt TOMANTSCHGER, Vjekoslav TADIĆ*
}

\begin{abstract}
During the recent years all crop species achieved the best possible field distribution so a high yield is to be expected. In this paper the solutions of two different diffusion equations are determined, which describe the optimal distribution of cereal grains over a field. Therefore, there are two different partial differential equations of cereal seed distribution-distinction is made between the longitudinal spacing (seeds in a row), and transverse distance (between two rows), as well as the sowing depth. In particular, closed forms of solutions are derived in each case. Although the result of the diffusion equation with respect to the distribution of the lateral seed distance of two adjacent rows is already known, a new solving method is presented in this paper. By this method, the partial differential equation is reduced to an ordinary one, which is easier to solve. In this paper it is shown that the distribution of lateral resp. longitudinal and in-depth wheat seed distances is achieved by a normal Gauss function resp. a log-normal function. Furthermore, it is demonstrated that the fitting functions of the best experimental results of wheat seeding distributions are particular solutions of the individual differential equations. Normal Gauss function describes lateral distribution with $R^{2}=0.9325 ; R S M E=1.2450$, and log-normal function describes longitudinal distribution with $R^{2}=0.9380 ; R S M E=1.4696$ as well as depth distribution with $R^{2}=0.9225 ; R S M E=2.0187$.
\end{abstract}

Keywords: analytical solutions; cereal seeds; diffusion equations; partial differential equation; probability density function

\section{INTRODUCTION}

In order to obtain the best possible harvest, all cereals (rye, barley, oats, beets, winter and spring wheat, etc.) must be sowed in straight rows at the correct distance from the grain in both the longitudinal and the transverse direction. The seed must also be sowed in correct depth of the soil. These distances vary from cereal to cereal and also depend on the climate. The irrigation of the arable lands also plays an important role. It also depends on which substances are contained in the soil at what percentage. Sowing of small grain crops is done by special seed drills.

In this paper, the optimal longitudinal (inter-row), lateral (intra-row) and depth seed distances of wheat in sowing is calculated and compared with the experimental results.

Before sowing, the soil contained $10 \%$ sand, $62 \%$ silt, $25 \%$ clay and $3 \%$ organic matter and was classified as Eutriccambisol according FAO/UNESCO rules [1]. The workable soil had no rocks or hard clay clods with a bit of harvested remains. Total yearly rainfall in this area was 720 $\mathrm{mm}$. Experiment was conducted on specified experimental plots and soil was prepared with heavy multitiller, disc harrowing and seedbed preparation.

Authors [2], perform similar research where the number of seeds per linear meter of furrow and the uniformity of the lateral distribution is measured and analysed. The uniformity of the depth of the wheat seed was also treated quite analogously. Also, some authors have researched the impact of the sowing system on number of plants per ha and achieved yield [3, 4].

Modern seed drills are equipped with monitoring systems that control most of their working parameters. Sensors enable easy collecting various spatial and temporal data, thus representing the important elements of precision agricultural production. For wheat sowing, Amazone Cirrus pneumatic seeding machine is used. For data and statistical processing, Microsoft Exel Professional Plus 2016 and SAS Enterprise Guide 7.1. is used.

Also in $[5,6]$ resp. there are experimental data concerning wheat seed and winter rye sowing.
Authors [7-14] are developing many different models with diffusion and differential equations for distribution of different properties as: waterborne particle sizes [8, 11, 14] and particle sizes of filter granulation [10, 12]. Also, different mathematical models are being developed for durability of agricultural tractors [7], surface roughness of artificial cell wall materials [9] and fertilizer particle motion [13]. Similar to the title of this paper, many authors are investigating seed distribution with different types sowing machines [15-18]. Also, the main problem of sowing is to determine longitudinal, lateral and depth seed distribution [17-21].

\section{DIFFUSION EQUATION REGARDING LENGTH AND DEPTH}

The parabolic partial differential equation describes this process. $y(x, t)$ denotes the probability density function of wheat seed distributions over length and depth. $x$ is the distance between two (adjacent) seeds or the depth of each seed. $t>0$ is the time. The constant $w$ represents a fitting parameter. The problem is to find the solution of this diffusion Eq. (1).

$$
\frac{\partial y}{\partial t}=\frac{w^{2}}{2}\left[x \frac{\partial y}{\partial x}+x^{2} \frac{\partial^{2} y}{\partial x^{2}}\right]
$$

Since no solution of the general diffusion equation has yet been found, one has to solve equation by equation. Taking the coefficients $c(x)=1 / x, D(x)=x$ and $F(x, t) \equiv 0$ it can be seen that Eq. (1) is a homogenous diffusion equation.

$c(x) \frac{\partial y}{\partial t}=\frac{\partial}{\partial x}\left(D(x) \frac{\partial y}{\partial x}\right)+F(x, t)$

To get an idea of how the solution of Eq. (1) might look like, Eq. (1) is simplified with the transformation:

$$
x=h(u)
$$


Replacing $x$ by the new variable $u$ implies:

$y(x, t)=y(h(u), t)=H(u(x), t)$

On substituting the derivatives of Eq. (1) into Eq. (1) one obtains:

$H_{t}=\frac{w^{2}}{2}\left[\left(x u^{\prime}+x^{2} u^{\prime \prime}\right) H_{u}+x^{2} u^{\prime 2} H_{u u}\right]$

To simplify this new form of the diffusion Eq. (1), is required. The general solution of Eq. (5) is given by:

$x u^{\prime \prime}+u^{\prime}=0$

$u(x)=C \ln x+C, x>0$

Since only a particular solution of Eq. (5) is needed, we put $C_{1}=1$ and $C_{2}=w^{2}-\ln \left(x_{0}\right) . x_{0}>0$ is any arbitrary constant. Thus:

$u=\ln \left(\frac{x}{x}\right)+w$ resp. $x=x e^{2}$

Hence, Eq. (4) possesses the form:

$H_{t}=\frac{w^{2}}{2} H_{u u}$

This equation can be solved in several ways $[2,4]$. In this paper, the solution of Eq. (7) is determined in a very special new way:

It can easily be shown that if $H(u, t)$ represents a solution of Eq. (7), the function:

$H(\beta u, \beta t)$,

where $\beta$ is an arbitrary constant, is also a solution of Eq. (7). This suggests the possibility of finding solutions for which for all $u$ and $t$. Now, for any particular value of $t$, it can always be taken $\beta=1 / \sqrt{t}$. So theidentity Eq. (8) means that:

$H(u, t) \equiv H\left(\beta u, \beta^{2} t\right)$

$H(u, t) \equiv H\left(\frac{u}{\sqrt{t}}, 1\right)=: F(z), z=\frac{u}{\sqrt{t}}$

for some function $F$. In fact, when we substitute Eq. (9) in Eq. (7) the partial differential Eq. (7) reduces to the ordinary differential equation:

$F^{\prime \prime}(z)+\frac{z}{w^{2}} F^{\prime}(z)=0$ which can be solved easier. In addition, it may be remarked that, Eq. (10) represents a first-order differential equation in $F^{\prime}$. This is an advantage, since ordinary differential equations are always easier to solve than partial ones. Eq. (10) implies:

$$
F^{\prime}(z)=A \exp \left[-\frac{z^{2}}{2 w^{2}}\right]
$$

with freely varying constant $A$. By differentiation of Eq. (7) with respect to $u$ one easily sees that $H_{u}$ represents a solution of Eq. (7) if $H(u, t)$ is a solution. This is a big advantage because $F$ and $H$ resp. no longer need to be calculated. On using $H_{u}=F^{\prime} / \sqrt{t}$ we obtain:

$H_{u}=\frac{A}{\sqrt{t}} \exp \left[-\frac{z^{2}}{2 w^{2}}\right]$

which also is a solution of the diffusion Eq. (7). Plugging back $z=u / \sqrt{t}$ and Eq. (6) gives:

$$
z=\frac{1}{\sqrt{t}}\left(\ln \left(\frac{x}{x_{0}}\right)+w^{2}\right)
$$

So Eq. (3) and Eq. (12) imply that:

$$
y(x, t)=\frac{A}{\sqrt{t}} \exp \left(-\frac{\left[\ln \left(\frac{x}{x_{0}}\right)+w^{2}\right]^{2}}{2 w^{2} t}\right)
$$

is a solution of the homogeneous differential Eq. (1) for any constant $A$.

\section{THE NORMALIZATION CONDITION}

For the computation of the arbitrary constant $A$, the normalization condition:

$\int_{0}^{\infty} y(x, t=1) \mathrm{d} x=1$

is used. Now the solution Eq. (13) is inserted into the integral and the exponent is squared. For the remaining integral with log-normal squared, the substitution $v=\ln \left(\frac{x}{x_{0}}\right)$ is performed. This leads to a well-known integral. That delivers:

$A=\frac{e^{\frac{w^{2}}{2}}}{w x_{0} \sqrt{2 \pi}}$ 
Since in the differential Eq. (1) only derivatives of $y$ occur, $y$ can be replaced by $y-y_{0}$, where $y_{0}$ is any arbitrary constant.

Thus, the final solution of the diffusion Eq. (1) is calculated and has the closed-form:

$y(x, t)=y_{0}+\frac{e^{\frac{w^{2}}{2}}}{w x_{0} \sqrt{2 \pi t}} \exp \left(-\frac{\left[\ln \left(\frac{x}{x_{0}}\right)+w^{2}\right]^{2}}{2 w^{2} t}\right)^{2}$

$y_{0}, x_{0}$ and $w$ are fitting constants which are different for the longitudinal and depth distribution of wheat seed.

\section{DIFFUSION EQUATION FOR LATERAL DISTANCE OF TWO ADJACENT SEEDS}

The differential equation:

$\frac{\partial y}{\partial t}=\frac{w^{2}}{8} \frac{\partial^{2} y}{\partial x^{2}}$

describes the lateral distribution of wheat seeds after machine seeding. Here the independent variable $x$ represents transverse (inter-row) seed distances. $t>0$ is the time. And $y=y(x, t)$ is again the probability density function of wheat seed distributions.

Eq. (16) can be solved in the same way as Eq. (7): Replacing in Eq. (7) $u$ by $x$, this yields $z=x / \sqrt{t}$ because of Eq. (9). Furthermore, $w$ in Eq. (7) is replaced by $w / 2$. So the solution Eq. (12) of Eq. (7) becomes:

$y(x, t)=\frac{A}{\sqrt{t}} \exp \left(-\frac{2 x^{2}}{w^{2} t}\right)$

resp.

$y(x, t)=y_{0}+\frac{A}{\sqrt{t}} \exp \left(-\frac{2\left(x-x_{0}\right)^{2}}{w^{2} t}\right)$

which is the solution of Eq. (16) for any new arbitrary constant $A . y_{0}, x_{0}$ and $w$ are fitting constants as in Eq. (15). It can be shown directly by substitution that the second function in Eq. (17) is a solution of Eq. (16).

Calculating the arbitrary constant $A$ with the normalization condition Eq. (14), one obtains

$A=\frac{1}{w} \sqrt{\frac{2}{\pi}}$

\section{EXPERIMENTAL RESULTS}

Measured probability density function values of wheat seed distribution are shown in Fig. 1 to Fig. 3. The shapes of these functions indicate that the lateral wheat seed distribution follows the well-known Gaussian normal distribution function (Fig. 1), while the shapes of the longitudinal and depth distributions are similar to the lognormal function (Fig. 2 and Fig. 3).

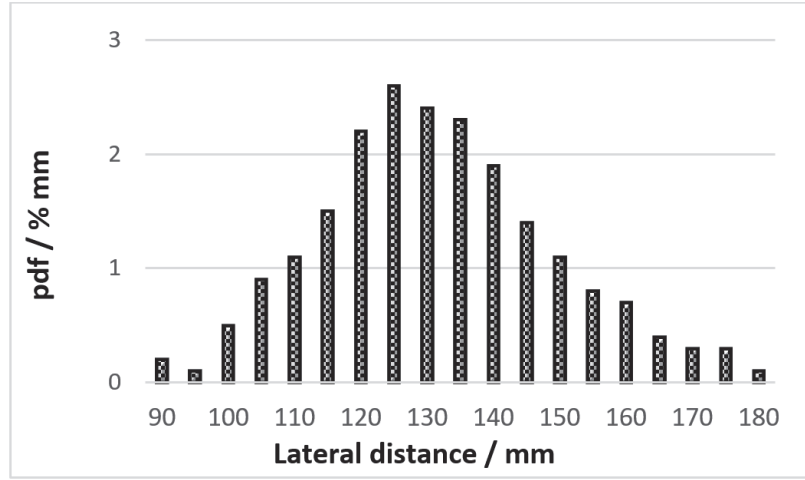

Figure 1 Probability density functions of wheat seed distribution over the width

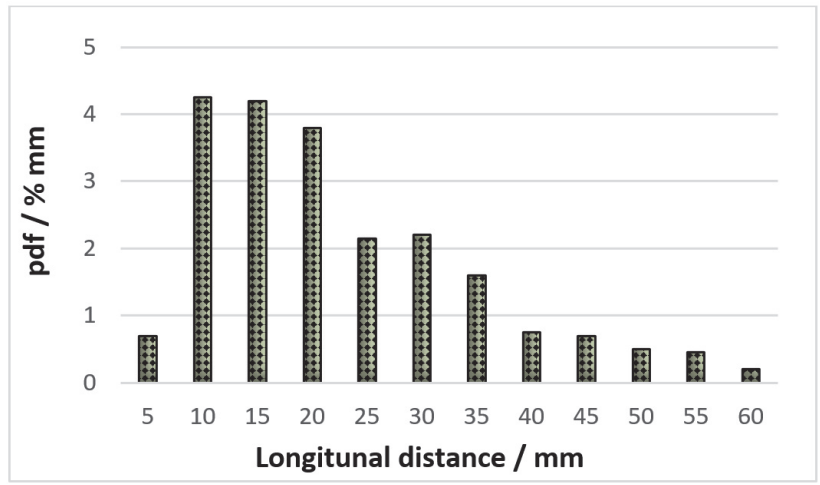

Figure 2 Probability density functions of wheat seed distribution over the length

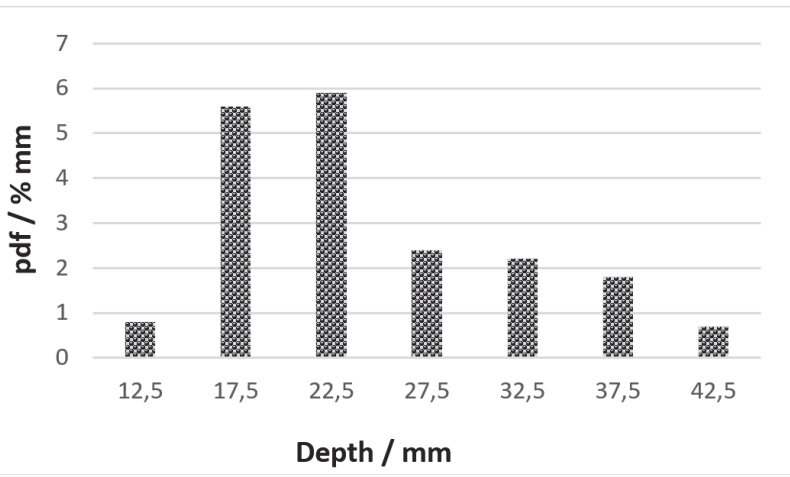

Figure 3 Probability density functions of wheat seed distribution over the depth

A variety of different fitting functions had been tested for the approximation of the probability density functions. Among these model functions, the functions:

$y(x)=y+\frac{A}{\sqrt{2 \pi} w x} \exp \left(-\frac{\left[\ln \left(\frac{x}{x}\right)\right]}{2 w}\right)$

(longitudinal seed distance and depth) and:

$y(x)=y_{0}+\frac{A}{\sqrt{\pi / 2} w} \exp \left(-\frac{2\left(x-x_{0}\right)^{2}}{w^{2}}\right)$ 
(lateral seed distance) have achieved the highest accuracy. In Fig. 4, distribution of seeds for all three functions is shown below.

Four fitting constants of these model functions Eq. (18) and Eq. (19), $x_{0}, y_{0}, w, A$ and the parameters (highest $R$-square, adjusted $R$-square values, smallest Root-meansquare errors) which characterise the fitting accuracy were calculated and are given in Tab. 1 . The $R$-square (or the socalled determination) index is very high in all three cases over 0.92 ; while all root mean square errors are very low.

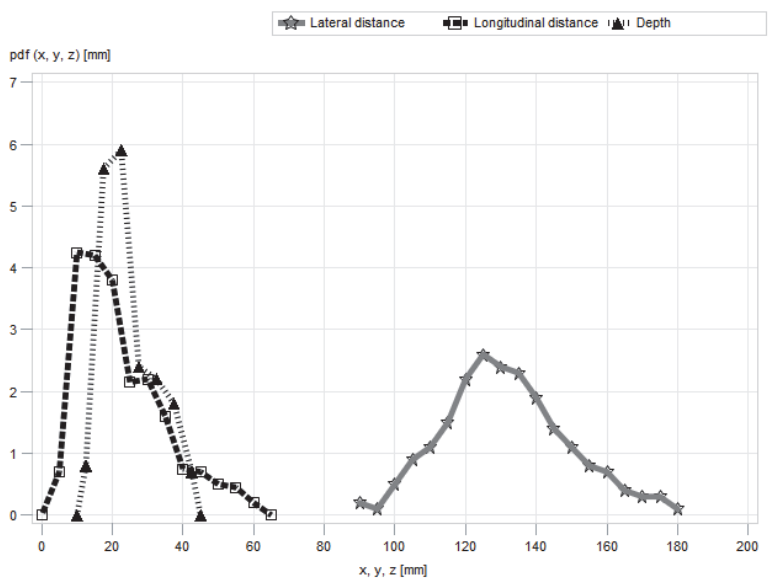

Figure 4 Distribution of wheat seeds over length, width and depth

Table 1 Coefficients of fitting functions and parameters characterizing the fitting accuracy

\begin{tabular}{|c|c|c|c|}
\hline & $\begin{array}{c}\text { Normal fit of } \\
\text { lateral } \\
\text { distribution }\end{array}$ & $\begin{array}{c}\text { Log-Normal fit of } \\
\text { longitudinal } \\
\text { distribution }\end{array}$ & $\begin{array}{c}\text { Log-Normal fit of } \\
\text { depth distribution }\end{array}$ \\
\hline$y_{0}$ & 0.0671 & -4.2318 & -6.4001 \\
\hline$x_{0}$ & 132.5420 & 15.3647 & 18.2570 \\
\hline$w$ & 29.2561 & 0.4781 & 0.2114 \\
\hline$A$ & 85.5991 & 156.3845 & 104.0078 \\
\hline$R^{2}$ & 0.9325 & 0.9380 & 0.9225 \\
\hline$R_{\text {adj. }}^{2}$ & 0.9256 & 0.9318 & 0.9070 \\
\hline$R S M E$ & 1.2450 & 1.4696 & 2.0187 \\
\hline
\end{tabular}

The area between the abscissa and the probability density function curve, is a \% participation of variable values between certain values $\left(x_{1}\right.$ and $x_{2}$, in millimetres in this study):

$p\left(x_{1}<x<x_{2}\right)=\int_{x_{1}}^{x_{2}}$ probability density function $(x) \mathrm{d} x$.

The experiments were carried out so accurately that both fitting Eq. (18) resp. Eq. (19) are even particular solutions of Eq. (15) resp. the second equation in Eq. (17) with $t=1$ of the partial differential Eq. (1) resp. Eq. (16).

\section{CONCLUSION}

A very important prerequisite for a good harvest is a high quality seed distribution when sowing over the area and depth. In this paper are presented and solved two partial differential equations which describe the probability density functions of wheat seeding over length and depth resp. the lateral distance of two adjacent seeds. It is shown that the solutions of these differential equations are the lognormal function and the Gaussian normal function.

The empirical determined data of the longitudinal and lateral distances, as well as the seed depths, were approximated and yielded experimentally determined probability density functions of wheat seeding over area and depth. The experimental fitting points of the probability density functions had been fitted following the least-squares fitting method to adjust the parameter values. These few parameters are constants in the assumed probability density function model, and are numerically evaluated by some sort of suitable fitting procedure.

The mathematical models, which are partial differential equations, had been experimentally verified by measuring the distances between two (adjacent) seeds or depth of each seed. The approximation of the probability density functions of wheat seed distributions over length, depth and lateral seed distance are exponential functions which are so accurate, that they even are the particular solutions $y(x, t=1)$ of the corresponding partial differential equations.

\section{REFERENCES}

[1] http://www.fao.org/home/en/

[2] Petrović, D. V., Tomantschger, K., \& Radojević, R. L. (2012). The Uniformity of Wheat Seeding over an Area and Depth. Proceedings of the $29^{\text {th }}$ Danubian-Adria Symposium, DAS, Belgrade-Zemun, Serbia,166-169.

[3] Banaj, A., Banaj, Đ., Tadić, V., Petrović, D., \& Stipešević, B. (2019). Impact of sowing system on maize grain yield of different FAO groups. Poljoprivreda, 25(2), 62-70. https://doi.org/10.18047/poljo.25.2.9

[4] Banaj, A., Banaj, Đ., Petrović, D., Knežević, D., \& Tadić, V. (2018). Impact of seeding system on the maize grain yield. Agronomski glasnik, 80(1), 35-48. https://doi.org/10.33128/ag.80.1.3

[5] Tomantschger, K., Paunesco, D., Petrović, D. V., Radojević R. L., \& Golubović Z. Z. (2013). Modelling the Lateral Uniformity of Wheat Seeding. $1^{\text {st International Symposium }}$ on Agricultural Engineering ISAE, Belgrade-Zemun, Serbia, $\mathrm{V}-21$.

http://isae.agrif.bg.ac.rs/archive/Proceedings_ISAE_2013.p df

[6] Barać, S., Petrović, D. V., Radojević, R. L., \& Tomantschger, K. (2016). Seed Spacing and Depth in Winter Rye Sowing. Savremena poljoprivredna tehnika, 42, 1-10. https://doi.org/10.5937/SavPoljTeh1601001B

[7] Tomantschger, K., Petrović, D. V., Golubović, Z. D., \& Mileusnić, Z. I. (2011). Differential equation model for durability of tractors with application to the model Massey Ferguson 8160.Afric. Jour. of Agric. Res., 6(18), 4385-4391. https://academicjournals.org/journal/AJAR/edition/12_Sept ember_2011

[8] Tasić, S. J., Golubović, Z. Z., Petrović, D. V., \& Golubović, Z. D. (2009). On the Applicability of Morphometric Method for Evaluation of the Waterborne Particles Size Distribution. Proceedings of $26^{\text {th }}$ Symposium on Advances in Experimental Mechanics, Leoben, 227-228. https://bib.irb.hr/datoteka/430011.Tagungsband_fertig.pdf\# page $=242$

[9] Petrović, D. V., Golubović, Z., Dajić, Z., Tomantschger, K., \& Radojević R. L., (2012). Mathematical Modelling the Surface Roughness Distribution of Artificial Cell Wall Materials, Facta Universitatis: Mechanical Engineering, 10, 1-6. http://facta.junis.ni.ac.rs/me/me201201/me20120101.pdf

[10] Tomantschger, K., Petrović, D. V., Golubović, Z. D., \& Trisović, N. (2012). Mathematical Model for the Particle Size Distribution of a Kieselguhr Filter Granulation. Metalurgia International, 17(10), 192-197.

[11] Golubović, Z. Z., Petrović, D. V., Golubović, Z. D., Tasić, S. J., \& Milosavljević, M. D. (2010). The Sice-Distribution 
of Solid Particles in a Technical Water. University of Belgrade - Faculty of Agriculture, Zemun-Belgrade, Serbia.

[12] Tomantschger, K., Petrović, D. V., Radojević, R. L., Golubović, Z.Z, \& Tadić, V. (2014). One-Dimensional Diffusion Equation for the Particle Size Distribution of Perlite Filter Granulation. Tehnički vjesnik-Technical Gazette, 24(3), 943-948. https://doi.org/10.17559/TV-20151202204533

[13] Tomantschger, K., Petrović, D. V., Cerović, V. B., Dimitrijević, A. Z., \& Radojević, R. L. (2018). Prediction of a Fertilizer Particle Motion Along a Vane of a Centrifugal Spreader Disc Assuming its Pure Rolling. FME Transactions, 46(4), 544-551. https://doi.org/10.5937/fmet1804544K

[14] Tomantschger, K., Petrović, D. V., \& Radojević, R. L. (2018). Determination of the Probability Size Distribution of Solid Particles in a Technical Water. Evaluations in Mechanical Engineering, 1(3), 514.

https://crimsonpublishers.com/eme/fulltext/EME.000514.ph $\mathrm{p}$

[15] Karayel, A. \& Zmerzi, O. (2007). Comparison of Vertical and Lateral Seed Distribution of Furrow Openers Using a New Criterion. Comparison of Research, 95, 69-75. https://doi.org/10.1016/j.still.2006.11.001

[16] Melo, R. W., Albiero, D., Praciano, A. C., Monteiro, L. D., $\&$ Garcia, A. P. (2019). Seed distribution by punch seeder in family framing. RevistaCienciaAgronomica, 50(3), 502-509. https://doi.org/10.5935/1806-6690.20190059

[17] Ferreira, F. M., Oss, L. L., Carneiro, M. D., \& Litter, A. (2019). Longitudinal distribution in the maize sowing in echanical and pneumatic precision seeding machines. Nativa, 3, 296-300. https://doi.org/10.31413/nativa.v7i3.7553

[18] Zhao, Z., Jin, M. Z., Tian, C. J., \& Yang, S. X. (2018). Prediction of seed distribution in rectangular vibrating tray using grey model and artificial neural network. Biosystems engineering, 175, 194-205. https://doi.org/10.1016/j.biosystemseng.2018.09.017

[19] Carpes, D. P., Alonco, A. D., Moreira, A. R., Possebom, G., Pires, A. D., Alonco, P. D., \& Zart, B. C. C. R (2018). Longitudinal distribution of soybean seeds with different methods of phytosanitary treatment by a horizontal perforated disc meter. Nativa, 6(5), 486-490. https://doi.org/10.31413/nativa.v6i5.5696

[20] De Silveira, P. M., Nascente, A. S., \& Da Silva, J. G. (2018). The effect of longitudinal distribution and seed depth on grain yield of common bean. Journal of seed science, 40(1), 90-97. https://doi.org/10.1590/2317-1545v40n178801

[21] Carpes, D. P., Alonco, A. D., Rossato, F. P., Veit, A. A., De Souza, L. B., \& Francetto, T. R. (2017). Effect of different conductor tubes on the longitudinal distribution of corn seeds. Revista Brasileira de Engenharia e Ambiental, 21(9), 657-662.

https://doi.org/10.1590/1807-1929/agriambi.v21n9p657-662

\section{Contact information:}

Kurt TOMANSCHGER, PhD, Associate professor

University of Technology Graz

Faculty of Mathematics, Physics and Geodesy,

Steyrergasse 30, 8010 Graz, Austria

E-Mail: tomantschger@tugraz.at

Vjekoslav TADIĆ, PhD, Associate professor

(Corresponding author)

University of J. J. Strossmayer in Osijek,

Faculty of Agrobiotehnical Sciences Osijek,

Vladimira Preloga 1, 31000 Osijek, Croatia

E-mail: vtadic@fazos.hr 